\title{
Hypermethylation of the promoter region of the E-cadherin gene $(C D H 1)$ in sporadic and ulcerative colitis associated colorectal cancer
}

\author{
J M D Wheeler, H C Kim, J A Efstathiou, M Ilyas, N J McC Mortensen, W F Bodmer
}

\begin{abstract}
Background-Ulcerative colitis associated colorectal cancer (UCACRC) has several distinctive clinicopathological and genetic features which differ from sporadic colorectal cancer (SCRC). Hypermethylation of the E-cadherin gene $(C D H 1)$ has not been described previously in colorectal cancer.

Aims-A panel of SCRC and UCACRC were investigated for mutations in $C D H 1$, and for hypermethylation of the promoter region of $\mathrm{CDH} 1$.
\end{abstract}

Subjects and methods-DNA was available from 14 patients with UCACRC and from 14 with SCRC. All exons of $C D H 1$ were amplified with the polymerase chain reaction (PCR) and screened using single strand conformational polymorphism and direct sequencing. Hypermethylation of the $C D H 1$ promoter region was determined by methylation specific PCR following bisulphite modification, and compared with E-cadherin protein expression from a previous immunohistochemistry study.

Results-Thirteen of 28 cancers (46\%) were hypermethylated in the $C D H 1$ promoter region-eight cancers $(57 \%)$ in the UCACRC group and five cancers $(36 \%)$ in the SCRC group (NS)-and this correlated with reduced $E$-cadherin expression $(p<0.05)$. There was a trend for methylation to be associated with a more advanced stage of cancer although this did not reach statistical significance. There were no mutations in $\mathrm{CDH} 1$ in either group although there were several polymorphisms.

Conclusion-We have demonstrated hypermethylation of the promoter region in $C D H 1$ in $46 \%$ of colorectal cancers studied. There was no difference between the UCACRC and SCRC groups. Just as there are specific differences in the genetic changes between UCACRC and SCRC, there is also likely to be a large degree of overlap among the genetic pathways of these cancers.

(Gut 2001;48:367-371)

Keywords: hypermethylation; promoter region; E-cadherin (CDH1); ulcerative colitis; colorectal cancer

Carcinogenesis is widely accepted as a multistep process. ${ }^{1}$ At each step, genetic or epigenetic alterations occur and can give tumour cells a selective advantage to expand their clones that evolve through an independent process at the somatic cell level. ${ }^{12}$ Colorectal cancers differ in their age at presentation, location, histology, and prognosis. As the adenoma to carcinoma pathway is accompanied by genetic events, ${ }^{3}$ there may be differences in the genetic pathways involved in the pathogenesis of distinct types of colorectal cancer.

The increased cancer risk in ulcerative colitis is well documented and is directly related to a long duration of disease and an early age of onset. ${ }^{45}$ Ulcerative colitis associated colorectal cancers (UCACRC) have several different clinicopathological features compared with sporadic colorectal cancer (SCRC). They usually arise from flat dysplasia or a dysplastic associated lesion or mass whereas SCRC usually arise from an adenomatous polyp. UCACRC usually occurs at an earlier age, is distributed relatively evenly along the entire colon, and is found to have an anaplastic or mucinous phenotype more frequently than not. These differences have led observers to suggest a difference in the genetic pathway between UCACRC and SCRC. Although mutations in $A P C, \mathrm{~K}$-ras, and TP53 are common in either UCACRC or SCRC, the observed mutation frequencies in these genes are somewhat lower in UCACRC. ${ }^{6-8}$ Differences in expression of p16 and Bcl-2 also hint at a different carcinogenesis pathway. ${ }^{9} 10$

One of the features of malignancy is invasion into the stroma and surrounding tissues. One of the molecules implicated in the progress of tumour invasion is E-cadherin, a $\mathrm{Ca}^{2+}$ dependent cell-cell adhesion molecule. In normal epithelium, E-cadherin is located in the basolateral membrane along the whole length of the crypt, and this plays a significant role in the development and maintenance of epithelial tissues. ${ }^{11} \mathrm{E}$-cadherin is encoded for by the $\mathrm{CDH} 1$ gene which is located on chromosome $16 \mathrm{q} 22$. In the cytoplasm, E-cadherin binds several undercoat proteins: $\alpha$ and $\beta$-catenin, and $\gamma$-catenin/plakoglobin, through which it connects to the actin cytoskeleton. ${ }^{12}{ }^{13}$ In addition, E-cadherin may affect the $\beta$-catenin associated intracellular signal pathway by competing with APC for binding to $\beta$-catenin. ${ }^{14}$ In inflamed tissue, E-cadherin expression is reduced to ensure the mobility of cells and healing of the

Abbreviations used in this paper: UCACRC, ulcerative colitis associated colorectal cancer; SCRC, sporadic colorectal cancer; RER, replication error; PCR, polymerase chain reaction; SSCP, single strand conformational polymorphism. 
ulcer. This phenomenon is well described in inflammatory bowel diseases such as ulcerative colitis and Crohn's disease..$^{15}$ Loss of expression and function of E-cadherin is associated with loss of differentiation and increased invasiveness in colorectal cancer. ${ }^{16}$

The E-cadherin gene $(C D H 1)$ is regarded as a tumour invasion/suppressor in epithelial cells, and mutations have been described in a number of epithelial cancers, including lobular breast and diffuse gastric cancers. ${ }^{17}{ }^{18}$ More recently, inactivating mutations in $\mathrm{CDH} 1$ have been described in human colorectal cancer cell lines. ${ }^{19}$ Hypermethylation in the promoter region in cancers has been described for a number of genes such as $p 16,{ }^{20}{ }^{21} V H L,{ }^{22}$ and $h M L H 1^{23}{ }^{24}$ and is usually associated with lack of expression of corresponding proteins in cancer. It has also been shown that E-cadherin expression is silenced by hypermethylation of the $C D H 1$ promoter region in a number of tumours, including breast, prostate, and hepatocellular carcinomas. ${ }^{25-27}$

In this study, we have sought additional evidence that UCACRCs may develop along a different pathway to that of SCRCs by investigating if there is any difference in the incidence of mutations in $C D H 1$ and hypermethylation of its promoter region between UCACRC and SCRC.

Material and methods

DNA from 14 UCACRCs and 14 SCRCs without a family history of colorectal cancer were accessed from the archives of the Imperial Cancer Research Fund, Oxford, UK.

The replication error (RER) status was determined by amplification of BAT 26 and BAT25 with fluorescent labelled primers and polymerase chain reaction (PCR) conditions, as previously described. ${ }^{28}{ }^{29}$ Essentially, $2 \mu$ of PCR product were mixed with $0.5 \mu$ of Rox size standard and $1 \mu \mathrm{l}$ of formamide loading buffer, heat denatured, and quenched on ice before being electrophoresed on a $6 \%$ acrylamide sequencing gel with a 377 Prism fluorescence based semiautomated sequencer (Applied Biosystems, Norwalk, Connecticut, USA). Results were analysed using Genescan 2.02 software (Perkin-Elmer, Norwalk, Connecticut, USA). All PCRs were repeated in duplicate and those tumours that were RER+ were confirmed using CA repeat markers D16S520 and D5S404.

POLYMERASE CHAIN REACTION AND SINGLE STRAND CONFORMATIONAL POLYMORPHISM (PCR-SSCP) ANALYSIS

All 16 exons of $C D H 1$ were amplified using previously published primers. ${ }^{17}$ All reactions were carried out in a total volume of $50 \mu \mathrm{l}$ with a final reaction concentration of $1 \times$ standard PCR buffer (Promega, Madison, Wisconsin, USA), $200 \mu \mathrm{M}$ dNTPs, $1.5 \mathrm{mM} \mathrm{Mg}, 0.2 \mu \mathrm{M}$ of each primer, and $1 \mathrm{U}$ of Taq polymerase. Due to the high content of GC nucleotides in exon $1,5 \%$ of DMSO was added. The amplicon spanning exons 4-5 was reduced to a size appropriate for SSCP by digesting the PCR product with $2 \mathrm{U}$ of $R s a \mathrm{I}$ enzyme and incubat- ing at $37^{\circ} \mathrm{C}$ for two hours. SSCP was performed as previously described..$^{30}$ Abnormal band shifts were compared with genomic DNA from 89 human random controls in the regions of interest (collected originally for a HLA allele frequency study, and supplied by Dr J Bodmer, Oxford, UK).

DIRECT SEQUENCING

If an abnormal band shift was observed on SSCP analysis, the nucleotide sequence was determined by direct sequencing, and the results analysed using a 377 Prism fluorescence based semiautomated sequencer (Applied Biosystems). The sequences were compared with published sequences using Sequencer 3.0 software.

METHYLATION SPECIFIC PCR

The methylation status of the $C D H 1$ promoter region was evaluated by performing methylation specific PCR of genomic DNA which had been purified following chemical treatment with sodium bisulphite, as described previously. ${ }^{22}$ Primer sequences for "unmethylated" and "methylated" methylation specific PCR of the $C D H 1$ promoter region and PCR conditions have been described previously. ${ }^{22} \mathrm{PCR}$ products were silver stained following 10\% polyacrylamide gel electrophoresis. The unmethylated breast cancer cell line MDA-MA468 , and the methylated breast cancer cell lines MDA-MA-231 and MDA-MA-435 were used as relevant controls. ${ }^{2526}$ All results were confirmed by duplicate analysis.

\section{STATISTICS}

Comparisons between the two groups were performed using the Wilcoxon rank sum test, Fisher's exact test, or the $t$ test using SAS software (v 6.11, SAS Institute Inc., North Carolina, USA). The relationship between promoter hypermethylation and reduced expression of E-cadherin was analysed using Fisher's exact test and the $\chi^{2}$ test .

\section{Results}

CLINICOPATHOLOGICAL FEATURES

Patients with UCACRC presented at a younger mean age than those with SCRC $(p=0.001)$. There was no significant difference between the two groups for other factors: sex distribution, differentiation, stage, or RER status (table 1). UCACRC was more commonly located in the right colon although this was not statistically significant.

RER STATUS

One UCACRC and two SCRC were found to be RER+ (table 1).

GENETIC CHANGES IN $C D H 1$

No mutation was identified in either UCACRC or SCRC. We found several polymorphisms, including intronic changes, namely single base substitutions in intron 2 , intron 4 , and intron 12, and a silent change at codon 692 $(\mathrm{GCC} \rightarrow \mathrm{GCT}$, Ala $\rightarrow$ Ala) (table 2). All polymorphisms were found in heterozygotes. The change in intron 2 (ctgggt $\rightarrow$ ctaggt) was a novel 
Table 1 Clinicopathological features and methylation status of promoter region in $\mathrm{CDH} 1$ in ulcerative colitis associated colorectal cancer (UCACRC) and sporadic colorectal cancer (SCRC)

\begin{tabular}{|c|c|c|c|}
\hline & $\begin{array}{l}\text { UCACRC } \\
(n=14)\end{array}$ & $\begin{array}{l}S C R C \\
(n=14)\end{array}$ & $p$ Value \\
\hline Age (mean (SD)) & $49(8.4)$ & $64.3(9.7)$ & 0.001 \\
\hline \multicolumn{4}{|l|}{ Location } \\
\hline Right colon & 6 & 3 & NS \\
\hline Left colon & 3 & 4 & NS \\
\hline Rectum & 5 & 7 & NS \\
\hline \multicolumn{4}{|l|}{ Differentiation } \\
\hline Well/moderate & 10 & 10 & NS \\
\hline Poor & 4 & 4 & NS \\
\hline \multicolumn{4}{|l|}{ Stage } \\
\hline Duke's A and B & 8 & 5 & NS \\
\hline Duke's C and D & 6 & 9 & NS \\
\hline \multicolumn{4}{|l|}{ RER status } \\
\hline+ & 1 & 2 & NS \\
\hline - & 13 & 12 & NS \\
\hline \multicolumn{4}{|l|}{ Methylation staus } \\
\hline+ & 8 & 5 & NS \\
\hline- & 6 & 9 & NS \\
\hline
\end{tabular}

change and only present in the UCACRC group. This change was not present in 80 human random controls. All other changes have been described previously. Differences in the frequencies of the polymorphisms between the two groups were not statistically significant.

\section{METHYLATION STATUS}

All 28 cancers showed PCR products for at least one unmethylated allele. Eight of 14 UCACRC and five of 14 SCRC showed PCR products for a methylated allele (fig 1). There was no significant difference in the frequency of methylated alleles between UCACRC and SCRC. When all cases combined were divided

Table 2 Summary of polymorphisms in CDH1 in ulcerative colitis associated colorectal cancer (UCACRC) and sporadic colorectal cancer (SCRC)

\begin{tabular}{lllll}
\hline & & \multicolumn{3}{l}{ Frequency } \\
\cline { 4 - 5 } Codon & Nucleotide change & Consequence & UCACRC & SCRC \\
\hline Intron 2 & ctgggt $\rightarrow$ ctaggt & - & 2 of 14 & 0 of 14 \\
Intron 4 & gaaag $\rightarrow$ gaaac & - & 3 of 14 & 3 of 14 \\
Intron 12 & attgc $\rightarrow$ actgc & - & 4 of 14 & 5 of 14 \\
692 & GCC $\rightarrow$ GCT & Ala $\rightarrow$ Ala & 10 of 14 & 8 of 14 \\
\hline
\end{tabular}

\section{UCACRC}
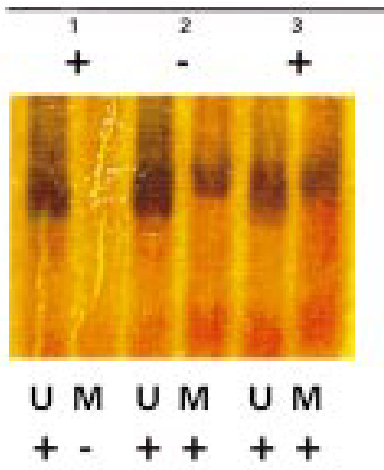

Table 3 Clinical features and replication error (RER) status in relation to promoter methylation

\begin{tabular}{|c|c|c|}
\hline & $\begin{array}{l}\text { Methylated } \\
(n=13)\end{array}$ & $\begin{array}{l}\text { Unmethylated } \\
(n=15)\end{array}$ \\
\hline \multicolumn{3}{|l|}{ Location } \\
\hline Right colon & 5 & 4 \\
\hline Left colon & 1 & 6 \\
\hline Rectum & 7 & 5 \\
\hline \multicolumn{3}{|l|}{ Differentiation } \\
\hline Well/moderate & 9 & 4 \\
\hline Poor & 4 & 11 \\
\hline \multicolumn{3}{|l|}{ Stage } \\
\hline Duke's A and B & 5 & 8 \\
\hline Duke's C and D & 8 & 7 \\
\hline \multicolumn{3}{|l|}{ RER status } \\
\hline+ & 1 & 2 \\
\hline - & 12 & 13 \\
\hline
\end{tabular}

None of the differences was statistically significant.

into methylated and unmethylated groups, there were no significant differences in pathological differentiation, stage, or RER status (table 3). However, advanced stage occurred more frequently $(61.5 \%$ of Duke's C and D in UCACRC and $46.7 \%$ in SCRC) with hypermethylation but this difference was not statistically significant.

METHYLATION STATUS AND ITS ASSOCIATION WITH E-CADHERIN PROTEIN EXPRESSION

Previous immunohistochemistry on these samples has shown similar patterns of E-cadherin expression (and $\mathrm{CDH} 1$ allele loss) between UCACRC and SCRC. ${ }^{31}$ In this previous study, those cases which showed membrane staining in more than $25 \%$ of tumour cells (grade $2 / 3$ ) were regarded as positive for E-cadherin expression. The immunohistochemistry data were then compared with the corresponding $C D H 1$ promoter methylation status from this study. Hypermethylation of the promoter region of E-cadherin correlated significantly with reduced E-cadherin immunohistochemical expression (Fisher's exact test, $\mathrm{p}=0.036 ; \chi^{2}$ test, $\left.\mathrm{p}=0.034\right)$. Eight of 11 grade $0 / 1$ tumours were methylated while 11 of 16

Figure 1 Silver staining of methylation specific polymerase chain reaction (PCR) products following electrophoresis on an acrylamide gel. Sample pairs 1-6 are from ulcerative colitis associated colorectal cancer (UCACRC), and 7-11 are from sporadic colorectal cancer (SCRC). E-cadherin protein expression is shown as present (+; grade 2/3) or absent (-; grade 0/1). Primer sets used for PCR amplification are designated as unmethylated (U) or methylated $(M)$, and a PCR product is shown as present $(+)$ or absent $(-)$. A PCR product is seen using unmethylated primers in the unmethylated breast cancer cell line, $M D A-M A-468$, and with methylated primers in the methylated breast cancer cell line, $M D A-M A-435$ (C=control). Hypermethylation of the promoter region of CDH1 correlated significantly with reduced E-cadherin immunohistochemical expression (Fisher's exact test, $p=0.036$ ). The methylated cancers that expressed E-cadherin protein may have been hemimethylated (methylation of one allele) and were therefore still able to express E-cadherin protein. 
Table $4 \quad$ E-cadherin expression and its relation to methylation status

\begin{tabular}{llllll}
\hline & $\begin{array}{l}\text { Grade } 0 \\
0 \%\end{array}$ & $\begin{array}{l}\text { Grade } 1 \\
1-25 \%\end{array}$ & $\begin{array}{l}\text { Grade 2 } \\
26-50 \%\end{array}$ & $\begin{array}{l}\text { Grade } 3 \\
>50 \%\end{array}$ & Not determined \\
\hline Methylated (13) & 0 & 8 & 1 & 4 & 0 \\
Unmethylated (15) & 1 & 2 & 7 & 4 & 1 \\
\hline
\end{tabular}

Scored semiquantitatively according to the proportion of stained tumour cells.

grade $2 / 3$ tumours remained unmethylated (table 4).

\section{Discussion}

We have previously described mutations in CDH1 in $8 \%$ of colorectal cancer cell lines. ${ }^{19}$ In the present study we did not find any mutation in $C D H 1$ in UCACRC or SCRC, although this may have been due to the relatively small sample numbers. Previous mutations were described in RER+ cell lines (33\%), and only three of our 28 samples were RER+. However, we detected hypermethylation in the promoter region in a significant proportion of colorectal cancers. Although, hypermethylation of the promoter region of $C D H 1$ is seen in more than $80 \%$ of papillary thyroid carcinomas, which is associated with reduced E-cadherin expression, ${ }^{32}$ hypermethylation of the $\mathrm{CDH} 1$ promoter was detected in only $46 \%$ of our samples. Fifty seven per cent of UCACRC and $36 \%$ of SCRC were hypermethylated but this difference was not statistically significant. Tumours with a hypermethylated promoter region did not have different clinicopathological features, such as advanced stage or poor differentiation. However, hypermethylation of the $C D H 1$ promoter was significantly associated with reduced or absent expression of E-cadherin protein $(p=0.036)$. Hypermethylation of the CDH1 promoter has not been described previously in human colorectal cancer. Yoshiura and colleagues ${ }^{33}$ studied a panel $^{2}$ of human carcinoma cell lines. However, only one cell line (SW1116) originated from the colon and was found to be unmethylated in the CDH1 promoter and to express E-cadherin mRNA.

Other work has shown that hypermethylation of the promoter region of $C D H 1$ in prostate, breast, and hepatocellular carcinoma is associated with reduced protein expression. ${ }^{25-27}$ Our results suggest that hypermethylation of the promoter region of $C D H 1$ in colorectal cancers is associated with a reduction in E-cadherin expression. This is similar to work using paraffin sections of thyroid and hepatocellular carcinomas where $\mathrm{CDH} 1$ promoter methylation is associated with a reduced intensity or heterogeneous pattern of E-cadherin expression. ${ }^{25} 32$

A PCR product was seen in all tumours with unmethylated primers, and it may be that some of our tumours were only partially methylated or hemimethylated (methylation of one allele), although this is difficult to examine as the tumours were not microdissected and are therefore contaminated with background stroma. Hence the unmethylated PCR product may be representative of this background stroma. It is also possible that there is a subpopulation of cancer cells that are hyper- methylated and do not in fact express E-cadherin, but that a further subpopulation of cells with no methylation do express E-cadherin. Four cancers that were found to have a hypermethylated $\mathrm{CDH} 1$ promoter also had grade 3 expression ( $>50 \%$ ) of E-cadherin protein. It is likely that these cancers were hemimethylated and were therefore still able to express E-cadherin protein. This has previously been described for the $h M L H 1$ gene and its protein in human colorectal cancer cell lines $^{34}$ which are not contaminated with background stroma.

Dosage effects, as a result of at least partial methylation of the $C D H 1$ promoter reducing expression of E-cadherin, may give a sufficient advantage for tumour outgrowth. If gene dosage to half function did not occur, or did not give a sufficient selective advantage, a dominant negative effect would be required to reduce the level significantly below half. However, we have not identified any mutation in these samples that could perform this function.

In conclusion, although we did not find mutations in $C D H 1$, we demonstrated hypermethylation of the promoter region in $C D H 1$ in $46 \%$ of colorectal cancers. Hypermethylation of $C D H 1$ has not been described previously in colorectal cancer but we have shown that this correlates significantly with reduced E-cadherin expression. This reduced expression of E-cadherin could be the basis for selecting hypermethylation of an allele during tumour progression. We have not shown a significant difference in E-cadherin expression, CDH1 mutations, or hypermethylation of its promoter between UCACRC and SCRC. Just as there are specific differences in the genetic changes between UCACRC and SCRC, there is also likely to be a large degree of overlap among the genetic pathways of these cancers. 1 Bodmer WF. The somatic evolution of cancer. The
Harveian Oration of $1996 . \mathcal{F} R$ Coll Phys Lond 1996;31:82-
9 .

2 Cairns J. Mutation selection and the natural history of cancer. Nature 1975;255:197-200.

3 Fearon ER, Vogelstein B. A genetic model for colorectal tumorigenesis. Cell 1990;61:759-67.

4 Levin B. Inflammatory bowel disease and cancer. Cancer 1992;70:1313-16.

5 Connell WR, Talbot IC, Harpaz N, et al. Clinicopathological characteristics of colorectal carcinoma complicating ulcerative colitis. Gut 1994;35:1419-23.

6 Chaubert P, Benhattar J, Saraga E, et al. K-ras mutations and p53 alterations in neoplastic and nonneoplastic lesions associated with longstanding ulcerative colitis. Am 7 Pathol 1994;144:767-75.

7 Tarmin L, Yin J, Harpaz N, et al. Adenomatous polyposis coli gene mutations in ulcerative colitis-associated dysplasias and cancers versus sporadic colon neoplasms. Cancer Res 1995;55:2035-8.

8 Itzkowitz SH. Inflammatory bowel disease and cancer. Gastroenterol Clin North Am 1997;26:129-39.

9 Fogt F, Vortmeyer AO, Goldman H, et al. Comparison of genetic alterations in colonic adenoma and ulcerative colitis-associated dysplasia and carcinoma. Hum Pathol 1998;29:131-6.

10 Ilyas M, Tomlinson IP, Hanby AM, et al. Bcl-2 expression in colorectal tumors: evidence of different pathways in sporadic and ulcerative-colitis-associated carcinomas. $A m \mathcal{F}$ Pathol 1996;149:1719-26.

11 Gumbiner B. Cell adhesion: The molecular basis of tissue architecture and morphogenesis. Cell 1996;84:345-57.

12 Gumbiner BM, McCrea PD. Catenins as mediators of the cytoplasmic functions of cadherins. F Cell Sci Suppl 1993;17:155-8

13 Reynolds AB, Daniel J, McCrea PD, et al. Identification of a new catenin: The tyrosine kinase substrate p120 cas associnew catenin: The tyrosine kinase substrate p120 12 cas associated with

14 Rubinfeld B, Souza B, Albert I, et al. Association of the APC gene product with beta-catenin. Science 1993;262:1731-4. 
15 Karayiannakis AJ, Syrigos KN, Efstathiou J, et al. Expression of catenins and E-cadherin during epithelial restitu18 .

16 Kinsella AR, Lepts GC, Hill CL, et al. Reduced E-cadherin expression correlates with increased invasiveness in color ectal carcinoma cell lines. Clin Exp Metastasis 1994;12:33542.

17 Berx G, Cleton-Jansen AM, Nollet F, et al. E-cadherin is a tumour/invasion suppressor gene mutated in human lobular breast cancers. EMBO $\mathcal{F} 1995 ; 14: 6107-15$.

18 Becker KF, Atkinson MJ, Reich U, et al. E-cadherin gene mutations provide clues to diffuse type gastric carcinomas. Cancer Res 1994;54:3845-52.

19 Efstathiou JA, Liu D, Wheeler JMD, et al. Mutated E-cadherin is associated with increased tumorigenicity, loss of adhesion and of responsiveness to the motogenic trefoil factor 2 in colon carcinoma cells. Proc Natl Acad Sci USA 1999;96:2316-21.

20 Merlo A, Herman JG, Mao L, et al. 5' CpG island methylation is associated with transcriptional silencing of the tion is associated with transcriptional silencing of the tumour suppressor p16/CD/

21 Herman JG, Merlo A, Mao L, et al. Inactivation of the CDKN2/p16/MTS1 gene is frequently associated with aberrant DNA methylation in all human cancers. Cancer Res 1995;55:4525-30.

22 Herman JG, Graff JR, Myöhänen S, et al. Methylationspecific PCR: a novel PCR assay for methylation status of CpG islands. Proc Natl Acad Sci USA 1996;93:9821-6.

23 Kane MF, Loda M, Gaida GM, et al. Methylation of the hMLH1 promoter correlates with lack of expression of hMLH1 in sporadic colon tumours and mismatch repair-defective human tumour cell lines. Cancer Res 1997; 57:808-11.

24 Herman JG, Umar A, Polyak K, et al. Incidence and functional consequences of hMLH1 promoter hypermethylation in colorectal carcinoma. Proc Natl Acad Sci USA ylation in colorecta
25 Graff JR, Herman JG, Lapidus RG, et al. E-cadherin expression is silenced by DNA hypermethylation in human breast and prostate carcinoma. Cancer Res 1995;55:51959.

26 Hiraguri S, Godfrey T, Nakamura H, et al. Mechanisms of inactivation of E-cadherin in breast cancer cell lines. Cancer Res 1998;58:1972-7.

27 Kanai Y, Ushijima S, Hui A, et al. The E-cadhrin gene is silenced by CpG methylation in human hepatocellular carcinoma. Int f Cancer 1997;71:355-9.

28 Hoang JM, Cottu PH, Thuille B, et al. BAT-26, an indicator of the replication error phenotype in colorectal cancers and cell lines. Cancer Res 1997;57:300-3.

29 Zhou XP, Hoang JM, Cottu P, et al. Allelic profiles of mononucleotide repeat microsatellites in control individuals and in colorectal tumors with and without replication errors. Oncogene 1997;15:1713-18.

30 Beck NE, Tomlinson IP, Homfray T, et al. Use of SSCP analysis to identify germline mutations in HNPCC families fulfilling the Amsterdam criteria. Hum Genet 1997;99:21924.

31 Ilyas M, Tomlinson IMP, Hanby A, et al. Allelic loss, replications errors and loss of expression of E-cadherin in colorectal cancers. Gut 1997;40:654-9.

32 Graff JR, Greenberg VE, Herman JG, et al. Distinct patterns of E-cadherin CpG island methylation in papillary, follicular, Hurthle's cell, and poorly differentiated human thyroid carcinoma. Cancer Res 1998;58:2063-6.

33 Yoshiura K, Kanai Y, Ochiai A, et al. Silencing of the E-cadherin invasion-suppressor gene by $\mathrm{CpG}$ methylation in human carcinomas. Proc Natl Acad Sci USA 1995;92: 7416-19.

34 Wheeler JMD, Beck NE, Kim HC, et al. Mechanisms of inactivation of mismatch repair genes in human colorectal cancer cell lines: the predominant role of $h M L H 1$. Proc Natl Acad Sci USA 1999;96:10296-301. 